\title{
Radical Anatomy, Seedling Morphology and Host Detection of Seedlings of Cassytha filiformis
}

\author{
Mahadevan N.* and Jayasuriya K.M.G.G. \\ Department of Botany, University of Peradeniya, Peradeniya, Sri Lanka \\ *niranja87@yahoo.com
}

\begin{abstract}
Seed biology is foster for ecologically sound management of parasitic weeds. The seedling which is the first vegetative phase of a plant after the germination has particular importance in the study of seed biology. Distance of parasite from the host plant, and germination morphology are two important aspects in life cycle of a parasitic plant. However, the little attention has been given to the study of germination biology of Cassytha filiformis. Thus, my study was conducted to identify the radical anatomy, seedling morphology, and minimal distance of the host to successful attachment of $C$. filiformis.

Manually scarified seeds were allowed to germinate on moisten filter papers and germinated radicals were collected in FAA solution and were used to study the anatomy of radicle using microtome sectioning. Another sample of seedlings was allowed to grow further and photographs were taken at different developmental stages. Some of selected seedlings were planted in soil media which are placed in three different distances from the host plants $(5 \mathrm{~cm}$, $10 \mathrm{~cm}$, and $15 \mathrm{~cm}$ ) and number of attached seedlings to their host and maximum days of survival without the aid of host was determined.
\end{abstract}

Anatomy of radical was similar to the general anatomy of typical dicotyledonous plant root which consist of outer epidermis, cortex and steal with an outer pericycle. After 5-6 days this is differentiated into 4 adventitious roots. A yellowish, conical hypocotyl is developed as continuous event of germination and this curved and formed a n-shaped loop in order to attach the substratum and to raise the cotyledon up. Thus the germination type is epigeal. According to the observations $100 \%$ of seedlings were attached to their respective host which was placed in $5 \mathrm{~cm}$ distance whereas about $60 \%$ of seedlings were able to attach where host was in $10 \mathrm{~cm}$ distance. $94 \%$ of seedlings were failed to attach their hosts in $15 \mathrm{~cm}$ distance. Attachment rates between $5 \mathrm{~cm}, 10 \mathrm{~cm}$ and $15 \mathrm{~cm}$ differ significantly $(\mathrm{F}=20.14, \mathrm{p}<0.001)$. Thus the minimal distance for successful attachment, host plant should be ranged from $5 \mathrm{~cm}$ to $10 \mathrm{~cm}$. And the seedlings can survive for about eight weeks without attaching a host using stored food reserves.

Keywords: Cassytha spp, Germination of seeds, Parasitic weed, Host location 